\title{
The association between smoking and tuberculosis
}

\author{
K.M. Hassmiller, MHSA. ${ }^{(1)}$
}

\begin{abstract}
Hassmiller KM.
The association between smoking and tuberculosis. Salud Publica Mex 2006;48 suppI I:S20I-S2I6.
\end{abstract}

\begin{abstract}
Objective. To review epidemiological evidence on the association between smoking and tuberculosis. Methods. Reviewed articles were identified by searching Pubmed for the terms "smoking" or "tobacco" and "tuberculosis". Additional articles were obtained from the bibliographies of identified papers. Results. Thirty-four studies were reviewed: five investigate the association between smoking and mortality from tuberculosis, I 3 investigate the association between smoking and development of tuberculosis, eigth investigate the association between smoking and infection with Mycobacterium tuberculosis, and nine estimate the impact of smoking on characteristics of tuberculosis and disease outcomes. Conclusions. Taken together, evidence suggests that smoking (both current and former) is associated with: risk of being infected with Mycobacterium tuberculosis, risk of developing tuberculosis, development of more severe forms of tuberculosis, and risk of dying of tuberculosis. In many cases, there is a strong dose-response relationship -both in terms of quantity and duration of smoking. These relationships are not explained away by controlling for potentially confounding variables such as age, gender, alcohol consumption, and HIV status.
\end{abstract}

Key words: Smoking; tobacco; tuberculosis

\author{
Hassmiller KM. \\ La asociación entre tabaquismo y tuberculosis. \\ Salud Publica Mex 2006;48 supl I:S20I-S2I6.
}

\section{Resumen}

Objetivo. Revisar evidencia epidemiológica relativa a la asociación entre el tabaquismo y la tuberculosis. Materiales y métodos. Se identificaron artículos de revisión mediante la búsqueda en Pubmed de los términos "tabaquismo","tabaco" y "tuberculosis". Se obtuvieron artículos adicionales de las bibliografías de los trabajos identificados. Resultados. Se revisaron 34 estudios: cinco investigan la asociación entre tabaquismo y mortalidad a partir de la tuberculosis; 13, la asociación entre tabaquismo y el desarrollo de tuberculosis; ocho, la asociación entre tabaquismo y la infección con Mycobacterium tuberculosis; y nueve estiman el impacto del tabaquismo en las características de la tuberculosis y las enfermedades resultantes. Conclusiones. En conjunto, la evidencia sugiere que el tabaquismo (tanto en la actualidad como en sus inicios) se asocia con lo siguiente: el riesgo a infectarse con Mycobacterium tuberculosis, el riesgo de desarrollar tuberculosis, de formas más severas de la misma, y con el riesgo de morir a causa de ella. En muchos casos, hay una fuerte relación dosis-respuesta, tanto en términos de cantidad como de duración del tabaquismo. Estas relaciones incluso se explican mediante el control de variables potencialmente confusoras como la edad, el género, el consumo de alcohol y la enfermedad del VIH.

Palabras clave: tabaquismo; tabaco; tuberculosis
$\mathrm{H}$ alf of all long-term smokers die prematurely due to smoking, and half of these deaths occur in middle age. ${ }^{1}$ It is known that tobacco smoking is a major risk factor for premature mortality from cancer, chronic obstructive pulmonary disease and cardiovascular disease. But as more research is conducted in developing nations, it is becoming evident that smoking is also a major risk factor for respiratory tract and other systemic infections. ${ }^{2}$ In fact, based on recent results in India, tuberculosis (TB) kills more than twice as many

(I) Department of Health Management and Policy. School of Public Health. University of Michigan. University of North Carolina, Department of Health Policy and Administration. USA.

Accepted on: March 6, 2006

Address reprint requests to: K.M. Hassmiller. Department of Health Policy and Administration. UNC-CH School of Public Health. I I07 McGavranGreenbrg, CB\#74II. Chapel Hill, NC 27599-74II.

Email: khassmil@umich.edu 
smokers as all forms of cancer combined. ${ }^{3}$ This finding likely generalizes to other populations where $\mathrm{TB}$ is highly prevalent.

Causing a quarter of all avoidable deaths, TB is the second largest cause of death from an infectious disease worldwide (after HIV), and is among the top 10 causes of illness, death and disability in terms of years of healthy life lost overall. ${ }^{4,5}$ One-third of the world's population is infected with Mycobacterium (M.) tuberculosis (the causative agent of TB). ${ }^{6}$ Ten to fifteen percent of those infected will develop active (symptomatic and infectious) TB sometime in their life. ${ }^{7-9}$ But these global statistics mask the fact that the dynamics of the spread of M. tuberculosis infection and patterns of disease vary greatly between geographic regions and subpopulations around the world. The majority $(95 \%)$ of all TB deaths occur in developing countries.

If smoking is indeed a risk factor for TB, it is a highly prevalent one. In 2003, an estimated 1.3 billion people smoked globally -approximately one third of all individuals at least 15 years old, ${ }^{10}$ and the burden of smoking is increasingly borne by developing countries. As smoking prevalence remains stable or is in decline in the developed world, it is on the rise in the developing world. In 2020, more than three quarters of projected deaths are expected to occur in developing countries. ${ }^{11}$ Further, the largest growth in smoking prevalence is occurring among women, particularly in low-income countries of Africa and Asia. ${ }^{12,13}$ These two epidemics -tobacco and TB are on a collision course. Understanding the impact of smoking on TB outcomes is critically important if we want to control TB.

Discussion of the association between tobacco consumption and TB has a long history. In the United States in the early 1900s, individuals who chewed tobacco were encouraged to switch to smoking. It was believed that spitting chewing tobacco resulted in transmission of $M$. tuberculosis, and that smoking cigarettes would improve public health. Ironically, this message may have inadvertently encouraged a more risky behavior. Several early studies conducted in England found an association between smoking and TB. ${ }^{14-16}$ Researchers generally argued that the association was due to an increased risk of having latent TB progress to active disease in smokers compared to nonsmokers. Using tuberculin skin test reaction as a proxy for disease risk (and indicating that an individual is infected with $M$. tuberculosis), evidence in the United States supported an association between tuberculin reactivity and parental smoking in children. ${ }^{17}$

Much of this early research was contended. Analyses were simple, and potential confounding variables -including alcohol consumption- were a great concern. ${ }^{18,19}$ Perhaps for this reason, or else because TB was growing less important as a public health concern in developed countries, little (if any) research was published on this association until the late 1980s -almost 20 years! Despite resurgence in research on the association between smoking and TB in the past 15 years, this link is still often unknown.

The purpose of this paper is to present findings on the association between smoking and TB from both developed and developing countries around the world, published since 1988. This review is much more upto-date and complete than existing reviews. ${ }^{2,20-22}$

Epidemiological studies fall into four categories based on the TB outcome they consider: the first section (Smoking and mortality from TB) reviews what is known about the association between TB mortality and smoking, the second section (Smoking and active TB) reviews the association between development of TB disease and smoking, the third section (Smoking and tuberculin skin test reactivity) reviews the association between infection with $M$. tuberculosis and smoking, and the fourth section (Smoking, characteristics of TB, and treatment outcomes) reviews the impact of smoking on characteristics of TB and outcomes. Because such factors as genetic susceptibility and environmental characteristics (for example crowding, climate, or exposure to environmental mycobacterium) are likely to affect the strength of the association between smoking and $\mathrm{TB}$, reviews are further categorized by country and/or subpopulation studied.

\section{Methods}

The terms "tuberculosis" and either "tobacco" or "smoking" were used to search the Pubmed database for relevant literature published after 1988. Pubmed is a service of the U.S. National Library of Medicine that includes all citations from MEDLINE and other sources (http:// www.ncbi.nlm.nih.gov/entrez/query.fcgi). Relevant references from articles obtained in this way were also reviewed. A total of 34 relevant articles were identified; the research design, definition of smoking utilized, and findings were reviewed for each. When possible relative risk (RR) and odds ratio (OR) values are presented with $95 \%$ confidence intervals -and presented as RR/ OR ( $95 \%$ confidence inverval). When confidence intervals are unavailable, p-values are presented (and labeled). Reviewed studies are summarized alphabetically by first author in each section, see tables I-IV.

\section{Epidemiological Evidence}

\section{Smoking and mortality from $\mathrm{TB}$}

China. Interested in the impact of tobacco use on mortality in mainland China, researchers conducted a 
Table I

Smoking ANd Mortality from Tuberculosis

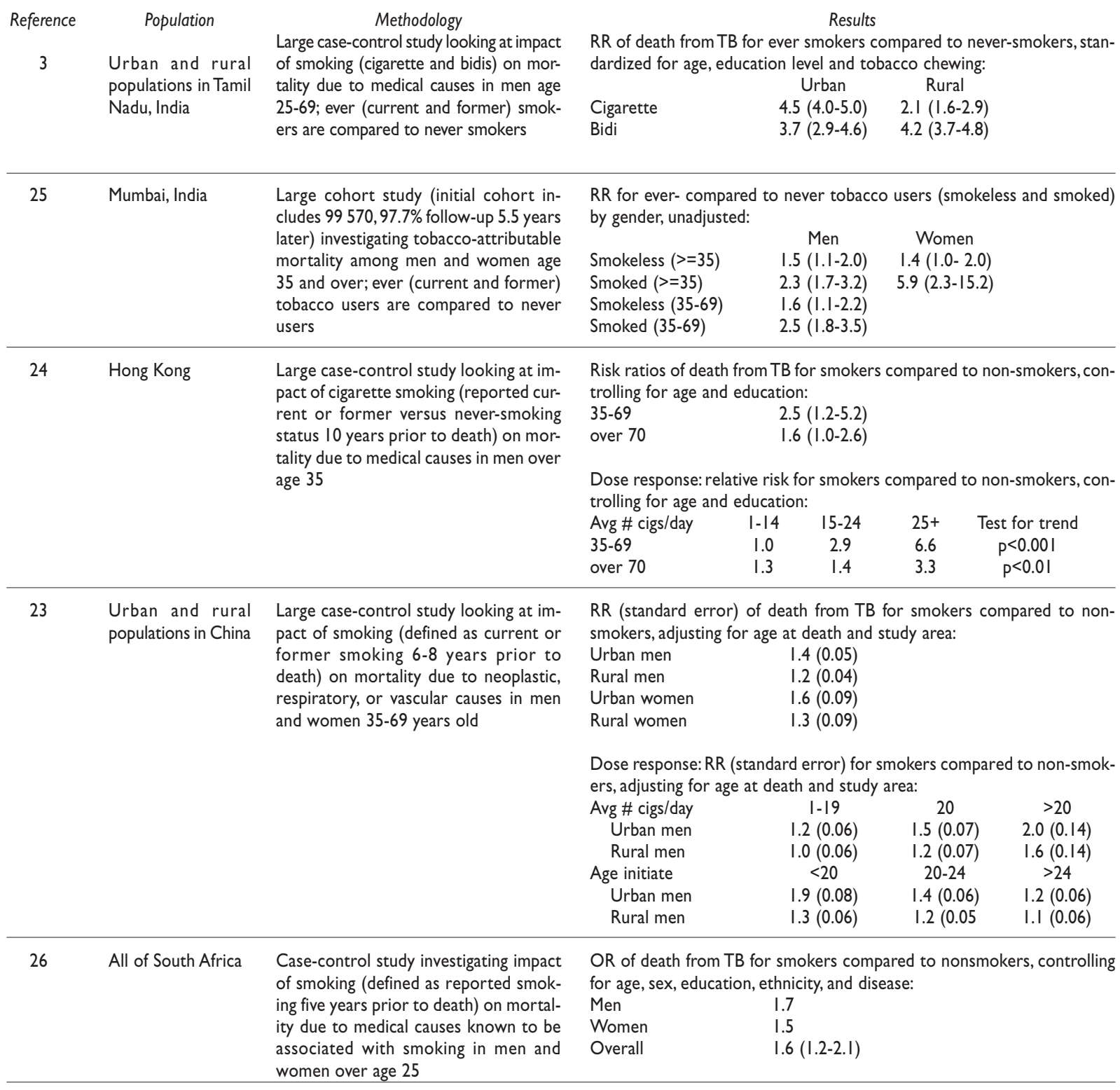

Notes: Unless otherwise stated, numbers in parentheses are $95 \%$ confidence intervals; $\mathrm{OR}=$ odds ratio and $\mathrm{RR}=$ relative risk.

large case control study in 24 Chinese cities and 74 randomly selected rural counties. ${ }^{23}$ Men and women aged 35-69 who died in any of the study areas between 1986 and 1988 were eligible for inclusion. The study included 3374 urban males, 4542 rural males, 1598 urban females, and 2652 rural females who died from respiratory TB. Controls were 30709 urban male, 22046 rural male, 21171 urban female, and 13389 rural female individuals who died of other causes, and for whom smoking habits before 1980 (6-8 years prior to death) could be obtained. Both current and former smokers were defined as smokers, though very little smoking cessation occurred in the study population. Adjusting for age at death and study area (a proxy for SES since individuals are roughly homogenous by SES within study areas), ever-smokers were more likely to die of TB than never-smokers in both urban and rural settings. Further, greater average daily quantity of ciga- 
rettes and earlier age of initiation were found to correlate with greater risk of death of respiratory TB in men.

A case-control study was conducted to assess the mortality associated with smoking in Hong Kong. ${ }^{24}$ Cases were all deaths (with known cause) of ethnic Chinese individuals over age 35 between mid-December 1997 and mid-January 1999 for whom a lifestyle survey was completed by the person registering the death $(27$ 507 cases). Controls were living males in the household who were over age 35 and not the person responding to the lifestyle survey (13 054 controls). Smokers were defined as individuals who were ever smokers (current or former) 10 years prior to death. There were 135 total TB deaths. Adjusting for age and education, ever-smokers of all ages are more likely to die of respiratory TB, though the increase is risk is greater among 35-69 year olds than it is among individuals over age 70. Further, a significant dose-response relationship was found for men in both age groups; the more cigarettes smoked per day, the higher was the risk of dying from respiratory TB.

India. Researchers conducted a retrospective case-control study in a large urban area (Chennai, population four million) and rural areas (2 000 villages in the district of Vilippuram, population 2.5 million) in the state of Tamil Nadu. ${ }^{3}$ Cases were individuals who died of medical causes during the survey period and whose family was available for interview to determine the individual's smoking behavior (16 076 males aged 25-69 in the urban area and 10121 in the rural area). There were 16488 urban and 13363 rural male controls aged 25-69 who were living members of households where a death was reported during the survey period. Urban deaths were tracked between 1995-1997, and rural deaths between 1997 and 1998. All analyses were standardized for age, education level and tobacco chewing. Ever-smokers -of both cigarettes and bidis in urban and rural environments- were significantly (and substantially) more likely to die of TB than never-smokers. A majority of TB deaths were determined to be associated with smoking (that is, attributed to individuals' smoking behavior) $-61 \%$ of urban and $56 \%$ of rural TB deaths. Though the excess mortality from TB was significant throughout all age groups, no clear pattern in relative risk by age was apparent.

Researchers conducted a cohort study in the densely populated city of Mumbai to estimate tobacco-associated mortality. ${ }^{25}$ Sampling from voter registration lists (oversampling low to middle-income areas), 99570 individuals at least 35 years of age were interviewed in their homes between February 1992 and May 1994. Between 1997 and 1999, 97244 individuals (97.7\%) were reinterviewed, and cause of death information was ob- tained for 5 470. Tobacco use status, ascertained in the first wave of data collection, was broken down into three mutually exclusive categories: current and former users of smokeless tobacco only, current and former smokers (cigarettes and bidis, may also use smokeless tobacco products), and lifetime never users. Both female and male ever-tobacco users were more likely to die of TB than female and male never-tobacco users (based on unadjusted estimation of relative risk).

South Africa. To investigate the impact of smoking on mortality in South Africa, researchers conducted a casecontrol study ${ }^{26}$ Starting in October 1998, all local Departments of Home Affairs submitted their first 200 death notifications. Of these ( $\mathrm{n}=16230)$, analysis was conducted on 5340 notifications for persons over age 25 of known gender and smoking status. Individuals were considered smokers if a close family member informant reported that the individual was a smoker five years prior to death. A total of 414 cases died from TB. Controls ( $n=1$ 124) were deaths from causess believed to be unrelated to smoking. Death notifications were excluded for: ill-defined causes, death due to causes strongly associated with alcohol, and death from external causes. Standardizing for age, education, population group, and sex, smokers were more likely to die of TB than non-smokers. In this population, more smoking-attributed deaths involved TB than lung cancer ( 87 and 57 , respectively), and an estimated $20 \%$ of TB deaths were attributable to smoking (based on attributable fraction percent calculation).

\section{Smoking and active $\mathrm{TB}$}

China. Researchers in Shanghai conducted a cross-sectional study of risk factors associated with the development of TB among employees of the Shanghai Bureau of Sanitation. ${ }^{27}$ Data come from a routine mass screening of the Bureau's employees, conducted between December 1985 and February 1986. Of the 30289 employees screened, 202 were found to have pulmonary TB. Adjusting for age, sex, history of contact, area of housing and type of work, heavy smokers were more likely to be diagnosed with pulmonary TB than non-smokers. Smoking accounted for observed differences in TB risk for men and adults age 50 and older.

Researchers in Hong Kong assessed the impact of smoking on the epidemiology and clinical presentation of TB. ${ }^{28}$ TB notifications were obtained from four chest clinics and two clustered chest hospitals in Hong Kong (26.6\% of the total notifications in 1996 from all of Hong Kong, $\mathrm{n}=851$ ). Smoking history and clinical characteristics were obtained from medical records. 
Table II

Smoking ANd Active Tuberculosis

\begin{tabular}{|c|c|c|}
\hline Reference & Population & Methodology \\
\hline 36 & Thailand & $\begin{array}{l}\text { Case-control study investigating the impact } \\
\text { of smoking (active and passive) on risk of } \\
\text { pulmonaryTB in HIV-negative individuals over } \\
\text { age I5; current active smokers report smok- } \\
\text { ing at the time of interview or within the pre- } \\
\text { vious six months, ex-active smokers report } \\
\text { smoking but not in the past six months, pas- } \\
\text { sive smokers are non active smokers (neither } \\
\text { current nor ex-active) exposed to environ- } \\
\text { mental tobacco smoke at least three times } \\
\text { per week }\end{array}$ \\
\hline 35 & Barcelona, Spain & $\begin{array}{l}\text { Case-control study investigating the impact } \\
\text { of active and passive smoking on risk of de- } \\
\text { veloping active TB among infected young } \\
\text { adults age I5-24 (exposure and infection con- } \\
\text { firmed in both cases and controls); active } \\
\text { smokers are individuals who report being cur- } \\
\text { rent smokers (either daily or less than daily) } \\
\text { and passive smokers report being exposed } \\
\text { to the combustion products of tobacco } \\
\text { smoked by others }\end{array}$ \\
\hline 34 & $\begin{array}{l}\text { Children under age } \\
\text { I } 5 \text { in Barcelona, } \\
\text { Spain }\end{array}$ & $\begin{array}{l}\text { Case-control study investigating the impact } \\
\text { of passive smoking on risk of developing ac- } \\
\text { tiveTB among infected children under age I } 5 \\
\text { (exposure and infection confirmed in both } \\
\text { cases and controls); passive exposure is de- } \\
\text { fined as exposure to combustion products of } \\
\text { tobacco smoked by others within six months } \\
\text { prior to survey }\end{array}$ \\
\hline
\end{tabular}

OR for those exposed to tobacco smoke compared to non-exposed (neither actively nor passively), adjusted for BMI:

Current active smokers

Ex-active smokers

Passive only 2.4 (0.9-6.0)

Ever-active, initiated <=age $20 \quad 3.2 \quad(1.2-8.8)$

Ever-active, smoked $>10$ years $\quad 3.0 \quad(\mathrm{I} . \mathrm{I}-8.2)$

Ever-active, avg $>10$ cpd $\quad 4.0(1.3-12.6)$

Ever-active, smoke $>3$ days/wk $\quad 2.7$ (I.0-7.I)

(Note: Ever-active includes current and ex-active who may or may not be exposed to passive smoke)

OR for young adults exposed to smoke compared to those unexposed (as described below), adjusted for age, gender, and SES:

$\begin{array}{lll}\text { Active only } & 3.6 \quad(p<0.0 I) \\ \text { Active and passive } & 5.1 \quad(p<0.01)\end{array}$

Dose response: OR based on amount smoked (average \# of cigs/day) compared to non-active smokers, adjusted for age, gender and SES: I-20 cigs/day $3.0 \quad(p<0.05)$

$>20$ cigs/day $\quad 13.0(p<0.001)$

OR for those exposed to passive smoke compared to those unexposed, controlling for age, sex, and father's social class: 5.4 (2.4-I I.9)

Dose response: OR based on number of parents smoking compared to non-exposed, unadjusted:

$\begin{array}{ll}\text { Mother only } & 4.2 \quad(p=0.04) \\ \text { Father only } & 4.2 \quad(p 0.001) \\ \text { Both } & 7.4 \quad(p<0.001)\end{array}$

Both

Dose response: OR based on average number of cigarettes smoked per day in the home compared to non-exposed, adjusted for age, sex, and father's social class:

$$
\begin{array}{ccc}
\text { I-20 } & 21-40 & >40 \\
\text { I.6 }(0.7-2.6) & 4.0(1.56-9.8) & 7.8(3.4-17.6)
\end{array}
$$

Age: OR by child's age for exposed vs. non-exposed, controlling for sex and father's social class:

$$
0-4 \quad 5-9 \quad 10-14
$$

I2.I (2.3-43.2) 10.2 (I.I-62.2) 3. I (0.8-II.3)

37 King County, WA, Case-control study investigating risk factors USA for diagnosis of active TB among adults (over age I8); smoking status (current, ex-, and never) is based on self-report

OR of diagnosis of active TB for smokers compared to never smokers, adjusted for age and alcohol consumption:

Ex-smokers I.4 (0.8-2.5)

Current smokers $\quad$ I.3 $(0.8-2.1)$

Dose response: Not significant for quantity smoked per day. The OR for developing TB for current compared to never smokers by duration of smoking, adjusting for age and alcohol consumption:

$$
\begin{array}{cccc}
1.9 \text { years } & 10-19 \text { years } & 20-29 \text { years } & 30+\text { years } \\
0.6(0.3-1.8) & 0.8(0.4-1.8) & 1.8(0.7-4.6) & 2.6(1.1-5.9)
\end{array}
$$

\begin{tabular}{ccl}
\hline 33 Northern Malawi & $\begin{array}{l}\text { Case-control study to examine risk factors } \\
\text { for diagnosis with tuberculosis in individuals } \\
\text { at least I5 years old; smoking status differen- } \\
\text { tiates self-reported never smokers, ex-smok- } \\
\text { ers, and current smokers }\end{array}$ \\
\hline $32 \quad$ Tamil Nadu, India & $\begin{array}{l}\text { Case-control study investigating the impact } \\
\text { of smoking on diagnosis with pulmonary TB } \\
\text { among men age 20-50; the study does not } \\
\text { clearly define smokers and non-smokers }\end{array}$
\end{tabular}

OR for smokers compared to never smokers, controlling for age, sex, area of residence, and HIV status:

Ex-smokers $\quad$ I.6 (0.7-3.2)

$<5 /$ day $\quad 0.9(0.5-1.7)$

$>=5 /$ day $\quad$ I.3 $(0.7-2.4)$

Age-adjusted odds ratio for smokers compared to non-smokers: 2.2 (1.3-3.9)

Dose response: OR based on quantity and years smoked compared to non-smokers ( $p<0.000$ I for each):

$\begin{array}{cccc}\text { Avg \# per day } & \mathrm{I}-\mathrm{I0} & \mathrm{II}-20 & >20 \\ \text { All men } & \mathrm{I} .8 & 3.2 & 3.7 \\ \text { \#Years smoke } & <10 & \mathrm{II}-20 & >20 \\ \text { All men } & 1.7 & 2.5 & 3.2\end{array}$




\section{Continuation}

39 West Africa (The Case-control study to investigate host and Gambia, Guinée environmental factors potentially associated Conakry, and Guin- with risk of developing smear-positive pulmoea Bissau) nary tuberculosis in individuals over age 15 ; smoking status differentiates past, current, and never-smokers

\begin{tabular}{|c|c|c|}
\hline 28 & Hong Kong & $\begin{array}{l}\text { Cross-sectional study to assess the impact } \\
\text { of smoking on epidemiology and characteris- } \\
\text { tics of TB; ever-smokers include both current } \\
\text { smokers (smokers who reported smoking at } \\
\text { the time of diagnosis/interview) and ex-smok- } \\
\text { ers (individuals who have smoked daily for a } \\
\text { continuous period of at least six months, but } \\
\text { no longer smoked at the time of diagnosis/ } \\
\text { interview) }\end{array}$ \\
\hline 29 & Hong Kong & $\begin{array}{l}\text { Prospective study of adults }>=65 \text { years old } \\
\text { to investigate the relationship between smok- } \\
\text { ing andTB; smoking status differentiates nev- } \\
\text { er-smokers (individuals who have never } \\
\text { smoked as many as one cigarette per day for } \\
\text { the duration of one year), current smokers } \\
\text { (individuals who smoked at least one ciga- } \\
\text { rette per day for at least one year and have } \\
\text { smoked within the past year), and ex-smok- } \\
\text { ers (former current smokers who have } \\
\text { stopped smoking for at least one year) }\end{array}$ \\
\hline
\end{tabular}

OR from analysis with household controls, controlling for age, gender, alcohol and drug use, HIV status, history of worms, and diabetes, for smokers compared to never-smokers:
Past smokers
$2.4(1.5-3.8)$

Current smokers

$3.1(2.4-4.2)$

OR from analysis with neighborhood controls, controlling for factors above plus other environmental factors including number of people in dwelling and ownership of home for smokers compared to never smokers:

Past smokers I.5 (I.I-2.I)

Current smokers $\quad 2.0(1.2-3.4)$

Dose-response relationship found for duration of smoking (data not shown)

OR of developing TB compared to never-smokers, controlling for age and sex:

Ever-smokers $2.4($ I.7-3.4)

OR removing TB cases who report consuming alcohol regularly, controlling for age and sex:

Ever-smokers

$1.9(1.4-2.7)$

Hazard ratios compared to never-smokers, adjusted for sex, age, alcohol use, language, marital status, education, housing, working status, public financial assistance status, monthly expenditures, participation in social activities, self-rated health status, hospital admission within 12 months, diabetes mellitus, chronic obstructive pulmonary disease, hypertension, heart disease, and cerebrovascular disease:

$\begin{array}{lcc} & \text { Current smoker } & \text { Ex-smoker } \\ \text { Active TB } & 2.6(1.9-3.70) & 1.4(1.0-2.0) \\ \text { New TB } & 2.6(1.8-3.80) & 1.4(1.0-2.0) \\ \text { Retreatment case } & 2.5(1.0-5.89) & 1.2(0.5-2.7) \\ \text { Pulmonary TB } & 2.9(2.0-4.11) & 1.4(1.0-2.0)\end{array}$

Hazard ratios of developing active TB compared to never-smokers,

adjusted for the same covariates above $(p=0.01)$ :
$<=4$
$5-9$
I. 5
$10-14 \quad>=15$
Current smoke
1.0
2.3
2.8

RR for long-term smokers compared to those who are not long-term smokers (defined as anyone who has not smoked for at least 20 years, including both non-long term current and former smokers, and nevpact of long-term smoking on development of TB in HIV-I infected patients

$$
\text { er-smokers): } \quad 3.0(p=0.04)
$$

\begin{tabular}{|c|c|c|}
\hline 31 & Estonia & $\begin{array}{l}\text { Case-control study that investigates the risk } \\
\text { factors for new diagnosis of pulmonary tuber- } \\
\text { culosis (including smoking) among individuals } \\
\text { over age } 15 \text {; smoking status is differentiated } \\
\text { into current, former, and non-smokers, though } \\
\text { precise definitions are not presented }\end{array}$ \\
\hline
\end{tabular}

OR of diagnosis with pulmonary TB for smokers compared to nonsmokers, controlling for place of birth, marital status, and education: Current smoker $\quad 4.6(2.4-8.7)$ Former smoker $\quad 2.3(1.0-5.1)$

OR for those exposed to passive smoking compared to those unexposed, controlling for place of birth, marital status and education: At home $2.3(1.3-4.2)$

OR for individuals who smoked for at least 30 years compared to those who did not, controlling for being born abroad, having visitors from country of birth, living with someone with tuberculosis, having more than one bathroom, having high blood pressure, and eating dairy products regularly:

$2.3(1.2-4.2)$

RR of TB diagnosis for heavy smokers compared to non-smokers, adjusted for age, sex, history of contact, housing and type of work: $2.2(1.3-3.6)$ Employees of Shang- Cross-sectional study of risk factors associ-
hai Bureau of Sani- ated with diagnosis of pulmonary TB; heavy tation smokers reported smoking more than 400 cigarettes per year while non-smokers reported smoking 0

(Notes: Unless otherwise stated, numbers in parentheses are $95 \%$ confidence intervals; $\mathrm{OR}=$ odds ratio and $\mathrm{RR}=$ relative risk.) 
Current smokers reported smoking at the time of diagnosis, and ex-smokers had smoked daily for a continuous period of at least six months, but no longer smoked at the time of diagnosis. These two groups comprised the ever-smokers. Population smoking prevalence rates (based on similar definitions) were obtained from the General Household Survey carried out in 1996 (a population survey of 3024 households). Standardizing for age and sex, the odds ratio for ever-smokers compared to never-smokers of developing TB was estimated as the ratio of the prevalence of smoking among the TB cases to the prevalence of smoking in the population. Ever-smokers were significantly more likely to develop TB than never-smokers. Because alcohol consumption data were not available in the General Household Survey, investigators recomputed the odds ratio above excluding TB cases who were regular alcohol users. Ever-smoking remained significantly related to risk of developing TB. The authors found that although smoking prevalence varied substantially between age and gender groups, the odds ratio of developing disease for ever-smokers compared to never-smokers did not.

A prospective study among a group of adults at least 65 years old was conducted to investigate the relationship between smoking and TB. ${ }^{29}$ A cohort of 42655 clients who registered with Hong Kong's Elderly Health Service in 2000 was followed prospectively through the TB notification registry through 2002. Of these, 286 incident cases of TB were notified and full data were available. Never-smokers were individuals who had never smoked as many as one cigarette per day for the duration of one year. Ever-smokers had smoked at least one cigarette per day for at least one year, and exsmokers were ever-smokers who had stopped smoking for at least one year. Current smokers were ever-smokers who had smoked within the past year. Of the 232 patients agreeing to voluntary HIV testing, only one patient was found to be HIV-positive. Hazard ratios were adjusted for sex, age, alcohol use, language, marital status, education, housing, working status, public financial assistance status, monthly expenditures, participation in social activities, self-rated health status, hospital admission within 12 months, diabetes mellitus, chronic obstructive pulmonary disease, hypertension, heart disease, and cerebrovascular disease. Compared to never-smokers, ex-smokers and current smokers were significantly more likely to develop active $\mathrm{TB}$, to have culture-confirmed TB, to have new TB (that is, first incidence of disease), to be a retreatment TB case, and, to have pulmonary involvement. A statistically significant dose-response relationship was found for number of cigarettes smoked per day. As much as $44.9 \%$ of the sexrelated difference in TB rates in this cohort can be attributed to smoking; smoking was responsible for $32.8 \%, 8.6 \%$, and $18.7 \%$ of TB risk among males, females, and the entire cohort, respectively (based on population attributable risk calculation).

England. Researchers in Liverpool conducted a case-control survey to investigate lifestyle risk factors associated with diagnosis of pulmonary TB. ${ }^{30}$ Cases were 112 individuals diagnosed with pulmonary TB. Controls were 198 individuals who were not tuberculin reactive and were matched to cases by street-based postcode, sex, date of birth (within three years), and ethnic origin. Individuals who reported smoking for at least 30 years were found to be significantly more likely to acquire pulmonary TB than those who did not smoke for at least 30 years, controlling for being born abroad, having visitors from country of birth, living with someone with $\mathrm{TB}$, having more than one bathroom (proxy for SES), having high blood pressure, and eating dairy products regularly. Alcohol consumption was not found to be associated with pulmonary TB in univariate analysis.

Estonia. Researchers conducted a case-control study to investigate risk factors for pulmonary TB. ${ }^{31}$ Cases were adults (over age 15) newly diagnosed with pulmonary TB at a hospital in Tallinn between January 1999 and June $2000(n=248)$. Controls were randomly selected from the Estonian Population Registry in July 2000, and were individually matched to cases by sex, year of birth, and county of residence $(n=248)$. Controls reporting a history of TB were excluded. Both passive and active exposure was found to relate to the risk of pulmonary $\mathrm{TB}$, after adjusting for place of birth, marital status, and education.

India. A group of researchers conducted a case-control study to investigate the association between smoking and diagnosis with pulmonary TB. ${ }^{32}$ Cases and controls were drawn from a survey of all persons, that was carried out in 30 villages from two areas of the Tiruvallur district of Tamil Nadu between 1993 and 1996. As smoking is extremely rare among Indian women, the study was restricted to men. Cases were men age 20-50 diagnosed with pulmonary TB. For every case, five men age 20-50 who tested negative for pulmonary TB were selected from the same village as controls. Tobacco use was ascertained by survey in 1998; 76\% of cases completed the tobacco use supplement, as did $83 \%$ of the controls, giving a sample of 85 cases and 459 controls. It is not clear, however, whether self-reported "smokers" included former or just current smokers, and what question was used to determine smoking status. Analysis was adjusted for age, and 
claimed that individuals from the rural villages surveyed were homogenous with respect to socio-demographic characteristics. Adjusting for age, smokers were more likely to develop TB, and this risk increased significantly with both increased average quantity smoked per day and duration of smoking.

Malawi. In northern Malawi, investigators conducted a case-control study to examine risk factors for development of TB. ${ }^{33}$ Cases were individuals with at least one smear or culture positive for acid-fast bacilli (AFB) and no previous $\mathrm{TB}$, at least 15 years old, and diagnosed between November 1996 and September 2001 ( $n=598)$. Controls were selected randomly from the population to have an age, sex, and area distribution similar to the cases, and no history of TB ( $\mathrm{n}=992)$. Controlling for age, sex, area of residence, and HIV status, smokers were not found to have a significantly different risk of being diagnosed with TB than nonsmokers. The authors suggested this finding may in part be due to the small sample of individuals with heavy exposure. In the entire study, only seven individuals smoked at least 20 cigarettes per day on average; six of these are cases.

Spain. A case-control study was conducted in Barcelona to investigate the impact of passive smoking on children under age 15 who had been infected with $M$. tuberculosis. ${ }^{34}$ Data were collected during 1992; cases and controls came from homes where one individual was diagnosed with pulmonary TB with positive sputum smear for AFB (the index). Cases were children diagnosed with pulmonary TB ( $n=93)$. Controls were tuberculin-reactive children with no evidence of pulmonary $\mathrm{TB}(\mathrm{n}=95)$. Care was taken to ensure that tuberculin reaction was not due to BCG vaccination. Assay of urinary cotinine concentration was used as an objective biomarker of exposure. Children were excluded if they: smoked; had previous history of tuberculosis infection or disease; had prior exposure to another index case; lived in an institution; or, had concurrent diagnosis of conditions identified as risk factors for TB, such as HIV infection, diabetes, or any other immuno-suppressing condition. Passive exposure was defined as exposure to combustion products of tobacco smoked by others within six months prior to survey. Adjusting for age, sex and father's social class, children exposed to passive smoke were more likely to develop pulmonary TB. The impact of passive smoke was stronger on younger children. Further, a dose-response relationship was found for both the number of smokers in the household and the average number of cigarettes smoked per day in the household.

The same group in Barcelona, using essentially the same methodology, conducted another study to investi- gate the impact of active and passive smoking among young adults on diagnosis of pulmonary TB. ${ }^{35}$ Forty-six cases age 15 to 24 who lived in a household with another infectious individual (index) were found to be tuberculin reactive and were diagnosed with pulmonary TB. Fortysix controls age 15 to 24 who were similarly exposed to an index case were also found to be tuberculin reactive but free of pulmonary TB. Daily smokers reported smoking a tobacco product every day at the time of the survey, while occasional smokers smoked a tobacco product less than once a day on average. A non-smoker did not smoke at all at the time of the study or in the six months before the index case was diagnosed. Controlling for social class, age, and gender, development of TB given tuberculin reactivity was found to be associated with active smoking. Further, a dose-response relationship was found for quantity smoked per day.

Thailand. A case-control study was conducted to investigate the association between active and passive smoking and TB. ${ }^{36}$ Cases were individuals at least 15 years old who were newly diagnosed with pulmonary TB between May and October 2001, and controls were agesex matched individuals without TB recruited from a local hospital and/or outpatient clinic during the same period. All participants were HIV- and DM-negative. Individuals with other lung diseases as indicated by physical examination and X-ray were excluded, resulting in 100 cases and 100 controls. Nonsmokers were persons who had never smoked (based on self-report) and were exposed to second-hand smoke less than three times per week. Current active smokers smoked at the time of the study or stopped smoking within six months (ex-active smokers quit at least six months prior). Passive smokers were non-active smokers exposed to tobacco smoke either at home, work, or in public places at least three times per week. Controlling for age, sex, and BMI, current active, ex-active, and passive smokers were more likely to be diagnosed with TB than nonsmokers, though the increase is only statistically significant for current active smokers. There was a significant dose-response relationship for both duration of smoking and quantity smoked (both cigarettes per day and number of days per week). Type of cigarette smoked (non-filtered/hand rolled or filtered) was not associated with risk of TB. Interestingly, passive smokers exposed outside the household were more likely to develop pulmonary $\mathrm{TB}$ than passive smokers exposed only within the household (who were not found to have a significant difference in risk of developing TB than nonsmokers).

United States. Researchers in Washington conducted a case-control study to identify risk factors for $\mathrm{TB} \cdot{ }^{37} \mathrm{~A}$ total 
of 151 cases were diagnosed with TB in the Seattle/King County Tuberculosis Clinic between 1988 and 1990 and were found to be competent for study, over age 18 , and never previously diagnosed or treated. A total of 545 controls were also screened at the clinic, and found not to have TB. After adjusting for age, age squared, and alcohol consumption, ex-smokers and current smokers were more likely to be diagnosed with TB than never smokers (no statistically significant). No significant doseresponse relationship was found for number of cigarettes smoked per day, but a significant dose-response relationship was found for duration of smoking.

A group of researchers sought to understand the impact of smoking on the development of opportunistic respiratory infection (including TB) in HIV-1 infected patients. ${ }^{38}$ Out of 259 HIV-1 infected subjects participating in a nutritional chemoprevention trial in Miami, Florida who were followed between 1998 and 2000, 12 developed TB. These 12 cases were compared to 27 controls with no history of respiratory infection, matched on age, gender, race, SES, and HIV status. Long-term smokers (smoke for 20 years or more) were more likely to develop TB than non longterm smokers. Lower CD4 cell counts were found in the cases as compared to the controls.

West Africa. A case-control study was conducted to investigate host and environmental-related factors believed to be associated with pulmonary TB. ${ }^{39}$ Cases were individuals over age 15 attending urban health centers in The Gambia, Guinée Conakry, and Guinea Bissau, with confirmed smear-positive pulmonary TB. For each case, two controls were selected: a healthy control within each case's household (687 case-control pairs), and a healthy community control within each case's neighborhood (816 case-control pairs). All controls were age matched to within ten years of the case. Based on analysis of cases and household controls and controlling for age, gender, marital status, family history of TB, alcohol consumption, drug use, BCG scar, HIV status, history of worms, and diabetes status, current and past smokers were found to be significantly more likely to develop smear-positive pulmonary TB than neversmokers. And, based on analysis of cases and neighborhood controls, controlling for the covariates included above and environmental factors including the number of households in the dwelling, the number of people in the household, the number of adults in the household, occupation, and ownership of house, current and past smokers were found to be significantly more likely to develop smear-positive pulmonary TB than never smokers. A clear dose-response relationship was found in terms of duration of smoking (data not shown).

\section{Smoking and tuberculin skin test reactivity}

England. A cross-sectional study was conducted to estimate the association between tuberculin reactivity (based on tuberculin skin test, TST) and length of time spent in a residential home for the elderly. ${ }^{40}$ All individuals residing in residential homes in Liverpool between January and June 1990 were given a tuberculin test and were asked about their smoking status. Heaf test positivity was stronger in current than in ex- and never-smokers. Further, heaf test positivity was directly related to number of pack-years smoked* for both current and ex-smokers.

Kuwait. Researchers investigated tuberculin reactivity among adults with and without pulmonary TB. ${ }^{41}$ Cases were patients admitted to Chest Hospital Kuwait for treatment for TB $(n=200)$. Controls were drawn randomly from the population of individuals attending routine residency screening for employment $(n=357)$. Individuals were excluded from the study if they were ex-smokers, HIV patients, or immunosuppressed due to long-term systemic steroids. Smoking was associated with induration (an indication of infection with $M$. tuberculosis) among controls, but was not found to be significantly different between smoking and non-smoking TB patients (who were known to be infected). Nonparametric analysis further demonstrated a significant correlation between induration and pack-years smoked among controls.

Pakistan. A cross-sectional study was conducted to assess the risk of $M$. tuberculosis infection and associated risk factors among prisoners. ${ }^{42} \mathrm{~A}$ random sample of 18 to 60 year-old men imprisoned between July and September 2002 in the five central prisons in the North West Frontier Province was included in the study $(n=425)$. Prisoners were excluded if they were sentenced to death, in solitary confinement, or within the first three months of their prison term. TST was conducted, and an induration of at least $10 \mathrm{~mm}$ in BCG unvaccinated prisoners and at least $15 \mathrm{~mm}$ in BCG vaccinated prisoners was the cutpoint for infection. There was a significant dose-response relationship between the number of cigarettes smoked and risk of infection, controlling for age, education, duration of incarceration, and type of accommodation.

South Africa. Researchers in Cape Town estimated the association between infection with M. tuberculosis and

\footnotetext{
* A pack-year is the product of the average number of cigarettes smoked per day and the number of years smoked divided by 20 .
} 


\title{
Table III
}

\section{Smoking and Tuberculin Skin Test Reactivity}

\begin{tabular}{|c|c|c|}
\hline Reference & Population & Methodology \\
\hline 41 & Kuwait & $\begin{array}{l}\text { Case-control study to investigate the } \\
\text { impact of smoking on TST induration; } \\
\text { smoking status differentiates current from } \\
\text { never-smokers, and excludes former- } \\
\text { smokers }\end{array}$ \\
\hline 46 & $\begin{array}{l}\text { Inmates in correc- } \\
\text { tional facilities in } \\
\text { South Carolina, } \\
\text { USA }\end{array}$ & $\begin{array}{l}\text { Case-control study to investigate the } \\
\text { impact of smoking on TST conversion; } \\
\text { smoking status (current vs. ex vs. never) } \\
\text { both at the time of interview and prior } \\
\text { to incarceration }\end{array}$ \\
\hline
\end{tabular}

\author{
Results
}

Median induration size for each group of controls (without active TB) found to be significantly different $(\mathrm{p}<0.00 \mathrm{I}), \mathrm{HIV}$-coinfected individuals excluded:

Current smokers $\quad 13.0(0-20.0)$

Never smokers $\quad$ II.0 $(0-20.0)$

No significant difference between current and never smoking cases (diagnosed with active TB)

Dose-response: Non-parametric correlation of PPD levels and pack-years smoked produces $r=0.323, p<0.00$

OR for TST conversion for current compared to never or ex-smokers, controlling for age and living conditions: I.8 (I.0-3.2)

OR of TST conversion by quantity currently smoked per day compared to never or ex-smokers, controlling for race, age, gender and living conditions:

I-10 cigarettes per day $\quad 1.9(1.0-3.7)$

$>10$ cigarettes per day $\quad 1.9(0.9-3.8)$

OR of TST conversion by quantity smoked prior to incarceration compared to never or past smokers, controlling for race, age, and living conditions:

I-20 cigarettes per day $\quad$ I.3 (0.8-2.3)

$>20$ cigarettes per day $\quad$ I. $8(0.8-3.7)$

OR of TST conversion by duration of smoking compared to never or past smokers, controlling for age, gender and living conditions:
$1-15$ years
I.6 (0.8-3.2)
$>15$ years
$2.1(1.0-4.4)$

\begin{tabular}{|c|c|c|c|}
\hline 43 & $\begin{array}{l}\text { Urban high TB in- } \\
\text { cidence areas in } \\
\text { Cape Town, South } \\
\text { Africa }\end{array}$ & $\begin{array}{l}\text { Cross-sectional population survey to in- } \\
\text { vestigate the impact of smoking on likeli- } \\
\text { hood of being TST reactive; pack-years } \\
\text { smoked are considered (for both current } \\
\text { and former smokers }\end{array}$ & $\begin{array}{l}\text { OR for current and ex-smokers compared to never-smokers of being TST } \\
\text { reactive (defined as induration }>=10 \mathrm{~mm}), \text { controlling for age and sex: } \\
\begin{array}{ll}<5 \text { pack-years } & 1.8(1.3-2.4) \\
5-15 \text { pack-years } & 1.8(1.3-2.5) \\
>=15 \text { pack-years } & 1.9(1.3-2.8)\end{array}\end{array}$ \\
\hline 42 & $\begin{array}{l}\text { Male prisoners in } \\
\text { the North West } \\
\text { Frontier Province, } \\
\text { Pakistan }\end{array}$ & $\begin{array}{l}\text { Cross-sectional study to investigate risk } \\
\text { factors for LTBI among male prisoners } \\
\text { aged } 16 \text { to } 60 \text {; smoking status is differen- } \\
\text { tiated between current smokers and cur- } \\
\text { rent non-smokers (never and ex) }\end{array}$ & 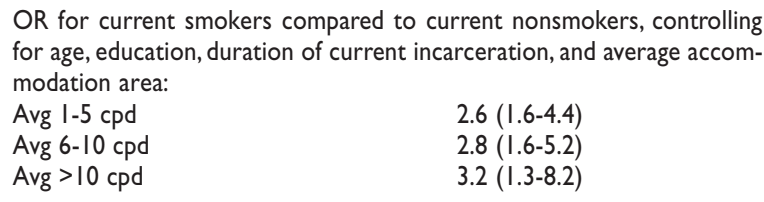 \\
\hline 45 & $\begin{array}{l}\text { Hispanic migrant } \\
\text { workers in CA, } \\
\text { USA }\end{array}$ & $\begin{array}{l}\text { Cross-sectional study investigating the } \\
\text { impact of smoking on TST induration; } \\
\text { smoking status differentiates former, cur- } \\
\text { rent, and never-smokers }\end{array}$ & $\begin{array}{l}\text { OR for smokers compared to never smokers: } \\
\text { Former smokers } \\
\text { Current smokers }\end{array}$ \\
\hline 40 & $\begin{array}{l}\text { Residential homes } \\
\text { for the elderly, Liv- } \\
\text { erpool, England }\end{array}$ & $\begin{array}{l}\text { Cross-sectional study investigating the } \\
\text { impact of length of stay in residential } \\
\text { home on tuberculin reactivity; distinguish- } \\
\text { es current, ex, and never-smokers }\end{array}$ & $\begin{array}{l}\text { OR of being heaf test positive for smokers compared to never-smokers, } \\
\text { unadjusted and significant at } p<0.05 \text { : } \\
\text { Current smokers } \\
\text { Ex-smokers } \\
\begin{array}{l}\text { Dose-response: Heaf test positivity directly related to pack-years smoked } \\
\text { (for both current and ex-smokers). }\end{array}\end{array}$ \\
\hline
\end{tabular}




\begin{tabular}{|c|c|c|c|}
\hline 47 & $\begin{array}{l}\text { Potential Vietnam- } \\
\text { ese migrants to } \\
\text { Australia (pre-de- } \\
\text { parture) }\end{array}$ & $\begin{array}{l}\text { Cross-sectional study investigating the } \\
\text { impact of smoking on TST induration; } \\
\text { smoking status differentiates current, } \\
\text { former, and never-smokers }\end{array}$ & 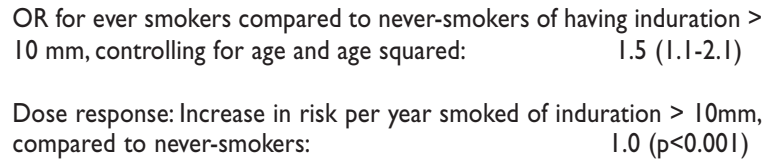 \\
\hline & & & $\begin{array}{l}\text { Dose response: No relationship between induration size and quantity } \\
\text { smoked per day. OR of induration }>=10 \mathrm{~mm} \text { by time since quitting com- } \\
\text { pared to current smokers, controlling for age, age squared and duration } \\
\text { of smoking: } \\
\begin{array}{ll}\text { Within } 10 \text { years } & \text { I.I }(0.6-2 . \mathrm{I}) \\
>10 \text { years prior } & 0.3(0.1-I . I)\end{array}\end{array}$ \\
\hline 44 & Barcelona, Spain & $\begin{array}{l}\text { A cross-sectional study to estimate the } \\
\text { prevalence of and assess risk factors for } \\
\text { infection among a population of home- } \\
\text { less; individuals who reported smoking } \\
\text { more than } 10 \text { cigarettes per day on aver- } \\
\text { age were considered smokers }\end{array}$ & $\begin{array}{l}\text { RR of infection for smokers compared to nonsmokers, controlling for } \\
\text { age, sex, and regular alcohol consumption: } \\
\text { Smoke }>10 \text { cpd on average } \\
\end{array}$ \\
\hline
\end{tabular}

(Notes: Unless otherwise stated, numbers in parentheses are $95 \%$ confidence intervals;

$\mathrm{OR}=$ odds ratio and $\mathrm{RR}=$ relative risk.)

smoking in a high TB incidence area. ${ }^{43} \mathrm{~A}$ total of 2328 adults over age 15 were interviewed at random in a cross-sectional population survey, and underwent a TST. Smoking was defined as having ever smoked for at least one year. The authors concluded that income did not confound the interaction between smoking and infection; after controlling for age and sex, smoking was associated with $M$. tuberculosis infection (defined as at least $10 \mathrm{~mm}$ induration). No statistically significant dose-response relationship for pack-years smoked was found.

Spain. Researchers estimated the prevalence of and risk factors for $M$. tuberculosis infection among the homeless in Barcelona. ${ }^{44}$ Between January 1997 and December 1998, 447 individuals admitted to homeless shelters or soup kitchens were tested for TST reactivity and active disease. Individuals who reported smoking more than 10 cigarettes per day on average were considered smokers. Controlling for age, sex, and regular alcohol consumption, smokers were more likely to be TST reactive (induration of at least $5 \mathrm{~mm}$ ) than nonsmokers.

United States. Researchers investigated tuberculin reactivity among Hispanic migrant workers in California. ${ }^{45}$ A total of 296 workers staying at either of the two Yolo County housing centers were interviewed and given a TST between July and September 1995. Controlling for age, gender, and location of birth (in versus outside of the United States), former smokers were significantly more likely to be infected (induration of at least $10 \mathrm{~mm}$ ) than migrant workers who had never smoked, though current smokers were not significantly more likely to be infected.
A case-control study was conducted in South Carolina to estimate the impact of smoking on TST conversion (reacting to TST after previously not, a condition indicative of recent infection). ${ }^{46} \mathrm{~A}$ total of 1245 inmates met the following inclusion criteria: from one of 11 correctional facilities in South Carolina, age 17-54 in 1990, admitted between January 1982 and December 1989, demonstrated to be TST non-reactive when incarcerated and tested again in 1990, and still incarcerated in 1992. Of these inmates, 116 who were TST converters (cases) and 177 race-matched non-converters (controls) were interviewed about their smoking status. TST-reaction was defined as at least $10 \mathrm{~mm}$ induration in HIV-negative and at least $5 \mathrm{~mm}$ induration in HIV-positive inmates. Potential confounding variables investigated included: exposure to an infectious case, length of time living in a high risk environment, age, race, gender, $\mathrm{MBI}$, education, employment history, use of alcohol or drugs, history of silicosis, diabetes status, HIV status, history of cancer, and utilization of immunosuppressive therapy. The authors controlled for variables they believed to be potential confounders (Table 3). Current smokers were not statistically significantly more likely to convert than never and ex-smokers. A dose-response relationship was found for both quantity currently and formerly smoked and risk of conversion, though these were also not statistically significant. However, a statistically significant doseresponse relationship was found for duration of smoking.

Vietnamese migrants. To investigate predictors of tuberculin reactivity, between January 1997 and June 1999, prospective Vietnamese migrants to Australia were recruited from a pre-departure standardized medical 
screening program. ${ }^{47} \mathrm{~A}$ total of 1395 participants completed a TST and structured interview including questions about socio-demographic indicators, living situation, and smoking behavior. Socio-demographic characteristics other than age and gender were not found to be significantly associated with tuberculin reactivity. Controlling for age, age squared, and gender, ever-smokes were significantly more likely to be tuberculin-reactive (induration of at least $10 \mathrm{~mm}$ ) than those who never smoked, and this risk increased with duration of smoking. Quitting at least 10 years prior was associated with a decreased risk of induration, though this finding was not statistically significant. No significant dose-response relationship was found for average quantity smoked per day.

\section{Smoking, characteristics of $\mathrm{TB}$, and treatment outcomes}

China. Investigators in Hong Kong conducted a nested case-control study to assess the risk factors for defaulting from anti-TB treatment under a directly observed treatment program. ${ }^{48}$ All patients registered at government chest clinics between January and March 1999 (excluding those who died or were transferred out) were included. Default was defined as failure to collect drugs for at least two months after registration, and three nondefaulting controls $(n=306)$ were age and sex-matched to each defaulting case $(n=102)$. Controlling for status as new or retreatment case, unsatisfactory adherence in the first 2 months, subsequent hospitalization, and treatment side effects in the last month of treatment, current smokers were significantly more likely to default than never-smokers, though ex-smokers were not significantly more likely to do so. Alcohol consumption, although correlated with smoking status, was not found to be associated with treatment default in univariate analysis.

In addition to estimating the association between smoking and diagnosis with TB (summarized above), Leung et al. ${ }^{28}$ assessed the impact of smoking on characteristics of TB. Controlling for sex, age, working status at onset of disease, history of narcotic abuse, co-existing medical illness and the absence of contact history within five years in logistic regression, ever-smoking TB cases were significantly more likely to present with a cough and difficult or labored breathing, and less likely to present with only extrathoracic TB than never-smoking TB cases. They were significantly more likely to have upper-zone involvement, cavitation, involvement, and a positive sputum culture than never-smoking TB cases.

India. A study conducted in the Tiruvallur District, Tamil Nadu, sought to understand the risk factors associated with relapse among patients who successful- ly completed treatment under DOTS and were considered "cured" (that is, smear-negative post treatment). ${ }^{49}$ This prospective study followed a cohort of new smearpositive pulmonary TB patients registered for DOTS between April 2000 and December 2001. Field workers collected sputum samples at 6,12 and 18 months post completion of treatment. Relapse was defined as a patient "cured" under DOTS who had either two separate sputum samples positive for AFB (including at least one positive culture). Controlling for initial drug resistance, alcoholism, and treatment irregularity smokers (habitual and current) were significantly more likely to relapse than nonsmokers.

An earlier study in the same district assessed risk factors associated with treatment default, treatment failure, and death among TB patients treated in a DOTS program. ${ }^{50} \mathrm{~A}$ total of 581 patients who registered for antiTB treatment in 209 villages and nine urban centers in the state of Tamil Nadu between May 1999 and April 2000 were included in analysis. Data do not show a clear association between smoking and treatment default when controlling for age, sex, previous treatment, pulmonary status, and alcoholism. However, the test is not very powerful given the small sample size and high correlation between smoking status and sex in this population. There is an association between smoking and both treatment default and failure (remaining sputum-positive after 3 months of treatment) based on univariate analysis. Smoking was not associated with risk of death from TB.

Saudi Arabia. Researchers investigated risk factors associated with treatment compliance in a non-DOTS population. ${ }^{52}$ Of 628 patients diagnosed with active TB in a large hospital in Saudi Arabia during 1996, 358 failed to attend their first appointment post discharge. Of these, attempts to bring the patient back to continue treatment by phone and visit by social worker failed for 275 patients. The characteristics of these patients, defined as non-compliant, were compared to the compliant patients. Based on univariate analysis, smokers were found to be significantly more likely to be noncompliant with treatment than nonsmokers.

Spain. A retrospective cross-sectional study was conducted in Cataluña, to establish whether there were differences in the characteristics and outcomes of TB experienced by smokers and nonsmokers..$^{53} \mathrm{~A}$ total of 13038 cases of TB were diagnosed in individuals over age 14 between January 1996 and December 2002. Patients who smoked at the time of diagnosis (or within days of diagnosis) were defined as smokers. After controlling for age, sex, alcohol consumption, and intra-venous drug use, smokers were significantly more likely to have cavitary lesions, positive 


\section{Smoking, Characteristics of Disease and Treatment Outcomes}

\begin{tabular}{|c|c|c|}
\hline Reference & Population & Methodology \\
\hline 52 & Saudi Arabia & $\begin{array}{l}\text { A cross-sectional study to investigate risk } \\
\text { factors for treatment non-compliance in } \\
\text { a non-DOTS control program; definition } \\
\text { of smoker is not presented }\end{array}$ \\
\hline 53 & Cataluña, Spain & $\begin{array}{l}\text { A cross-sectional study to establish } \\
\text { whether characteristics of disease and } \\
\text { outcomes differ between smoking and } \\
\text { nonsmoking TB patients age I } 5 \text { or over; } \\
\text { TB patients who smoked at the time of } \\
\text { diagnosis and those who stopped smok- } \\
\text { ing within days of diagnosis (due to symp- } \\
\text { toms) were defined as smokers and the } \\
\text { rest as nonsmokers }\end{array}$ \\
\hline
\end{tabular}

Results

RR of non-compliance for smokers compared to nonsmokers (univariate analysis): I.3 $(p=0.0003)$

OR for smokers compared to nonsmokers, controlling for age, sex, alcohol consumption, and IVDU:

$\begin{array}{ll}\text { Having cavitary lesions } & \text { I.9 }(1.6-2.3) \\ \text { Being smear-positive } & \text { I.4 (I.3-I.6) }\end{array}$

Being smear-positive
Having pulmonary TB

$1.5(1.3-1.6)$

OR for smokers compared to nonsmokers, controlling for age, sex, alcohol consumption, and disease site:

Being hospitalized for disease

$1.8(1.5-2.2)$

Smokers stay in the hospital an average of 9.4 days longer than nonsmokers; there is no significant difference in the delay before diagnosis or in the risk of death from disease between smokers and nonsmokers; males smoked twice as much as females - likely explaining gender effects and suggesting a dose-response relationship

Logistic regression coefficient for adherence among current non-smokers relative to current smokers, controlling for age, gender, occurrence of family screening, whether the case is new or relapse, presence of cough, hemoptysis, or cavity, and smear-status:

Current non-smokers $\quad \mathrm{I} .5(\mathrm{p}=0.006)$ DOTS; a clear definition of smoking staferentiated into "yes" or "no"

\begin{tabular}{|c|c|c|c|}
\hline 48 & Hong Kong & $\begin{array}{l}\text { Nested case-control study to assess the risk } \\
\text { factors for defaulting from anti-tuberculosis }\end{array}$ & $\begin{array}{l}\text { OR for ever-smokers compared to never-smokers, controlling for retreat- } \\
\text { ment status, adherence in first } 2 \text { months, hospitalization, and side effects: }\end{array}$ \\
\hline & & treatment under a directly observed & Current smokers \\
\hline & & $\begin{array}{l}\text { treatment program; smoking status is self- } \\
\text { reported and differentiates current from } \\
\text { former and never-smokers }\end{array}$ & $1.8(0.7-4.8)$ \\
\hline 56 & NYC,United States & $\begin{array}{l}\text { As part of a case-control study to evalu- } \\
\text { ate the impact of incentives on treatment } \\
\text { adherence, researchers conducted a } \\
\text { cross-sectional analysis to identify risk } \\
\text { factors for failure to adhere to TB treat- } \\
\text { ment; self-reported current smokers } \\
\text { were compared to all others }\end{array}$ & $\begin{array}{l}\text { RR of failing to adhere to treatment for smokers compared to nonsmok- } \\
\text { ers (univariate analysis): }\end{array}$ \\
\hline \multirow[t]{9}{*}{28} & \multirow[t]{9}{*}{ Hong Kong } & $\begin{array}{l}\text { Cross-sectional study to assess the im- } \\
\text { pact of smoking on epidemiology and } \\
\text { characteristics of TB; ever-smokers in- } \\
\text { clude both current smokers (smokers }\end{array}$ & $\begin{array}{l}\text { Clinical variables predicted by ever-smoking status, controlling for age, } \\
\text { sex, working at onset of disease, regular alcohol use, history of narcotic } \\
\text { abuse, co-existing medical conditions, and absence of contact history within } \\
\text { five years: }\end{array}$ \\
\hline & & who reported smoking at the time of di- & Present with cough \\
\hline & & agnosis/interview) and ex-smokers (indi- & Present with dyspnoea \\
\hline & & viduals who have smoked daily for a & Only extrathoracic disease \\
\hline & & continuous period of at least six months, & Have upper-zone involvement \\
\hline & & but no longer smoked at the time of di- & Have cavitation \\
\hline & & agnosis/interview) & Have miliary involvement \\
\hline & & & Positive sputum smear \\
\hline & & & Positive sputum culture \\
\hline 54 & Istanbul, Turkey & $\begin{array}{l}\text { Cross-sectional study to compare factors } \\
\text { influencing site of TB; ever (current and } \\
\text { former) smokers are compared to never } \\
\text { smokers }\end{array}$ & $\begin{array}{l}\text { OR of extra-pulmonary (versus pulmonary) TB for ever compared to never } \\
\text { smokers, controlling for gender, contact history, diabetes status, and alco- } \\
\text { hol consumption (all participants HIV-negative): } 0.5(p=0.025)\end{array}$ \\
\hline
\end{tabular}




\section{Continuation}

\begin{tabular}{|c|c|c|c|}
\hline \multirow[t]{3}{*}{50} & Tamil Nadu, India & $\begin{array}{l}\text { A cross-sectional study to assess risk fac- } \\
\text { tors associated with treatment default } \\
\text { and failure, and death from TB within a } \\
\text { DOTS program }\end{array}$ & $\begin{array}{l}\text { RR of defaulting from treatment for smokers compared to nonsmokers } \\
\text { (univariate analysis): } \\
\text { No significant difference was found in risk of defaulting for smokers com- } \\
\text { pared to nonsmokers after controlling for age, sex, previous treatment, } \\
\text { pulmonary status, and alcoholism }\end{array}$ \\
\hline & & & $\begin{array}{l}\text { RR of failing treatment for smokers compared to nonsmokers (univariate } \\
\text { analysis): } \quad 8.4(1.0-388)\end{array}$ \\
\hline & & & $\begin{array}{l}\text { No significant difference was found in the risk of death given disease for } \\
\text { smokers compared to nonsmokers }\end{array}$ \\
\hline 49 & Tamil Nadu, India & $\begin{array}{l}\text { Prospective study to look at predictors } \\
\text { of relapse among previously recovered } \\
\text { smear+ pulmonary TB patients over age } \\
15 \text {; individuals who habitually and current- } \\
\text { ly smoke are classified as smokers, and } \\
\text { the rest as nonsmokers }\end{array}$ & $\begin{array}{l}\text { OR of relapse for smokers compared to nonsmokers, controlling for al- } \\
\text { coholism, initial drug resistance and treatment irregularity: } 3.1 \text { (I.6-6.0) }\end{array}$ \\
\hline
\end{tabular}

(Notes: Unless otherwise stated, numbers in parentheses are $95 \%$ confidence intervals;

$\mathrm{OR}=$ odds ratio and $\mathrm{RR}=$ relative risk.)

bacilloscopy, and pulmonary TB than nonsmokers. After controlling for age, sex, alcohol consumption, and disease site, smokers were significantly more likely to be hospitalized, and to be hospitalized an average of 9.4 days longer than nonsmokers. Smokers did not take longer to get diagnosed than nonsmokers, however their disease appeared to have progressed faster upon diagnosis. Smokers were not significantly more likely to die from TB. The authors also found that male smokers smoked twice as much as female smokers, likely accounting for a substantial portion of the significant gender effects in the analysis.

Turkey. A cross-sectional study was conducted in Istanbul to compare factors influencing TB site. ${ }^{54}$ Participants were all individuals over age 12 treated at the Istanbul University Cerrahpasa Medical Faculty Pulmonology Department Tuberculosis Polyclinic between May 1997 and August 2004, who did not have both pulmonary and extrapulmonary $\mathrm{TB}$, miliary or primary TB ( $n=375$, all HIV-negative). Controlling for gender, history of contact, diabetes status, and alcohol use, individuals with a history of smoking (current or former) were significantly less likely to develop extrapulmonary (versus pulmonary) TB than never smokers.

Another cross-sectional study was conducted in Duzce to investigate risk factors for non-adherence to TB treatment in a population without DOTS. ${ }^{55} \mathrm{~A}$ total of 154 patients at least 16 years old who were diagnosed with drug-sensitive TB between October 1998 and October 2003 were included in the study. Non-adherent patients were those who: failed to keep clinic appointments for at least two consecutive months, failed to keep three or more monthly visits in the course of one year, or refused treatment from the start. Controlling for age, gender, occurrence of family screening, whether the case was new or a relapse, smear status, or the presence of cough, hemoptysis, or cavity, nonsmokers were significantly more likely to adhere to treatment.

United States. In a trial to investigate the impact of incentives on treatment compliance, researchers in New York City assessed risk factors for adherence. ${ }^{56} \mathrm{~A}$ total of 365 patients from six directly observed therapy centers who received treatment between 1992 and 1996 were included in analysis. Adherent patients were defined as those who attended $80 \%$ of their prescribed visits every month during the course of their treatment. ${ }^{57}$ Based on univariate analysis, self-reported smokers were found to be significantly less likely to adhere than non-smokers. Smoking was not associated with differential odds of adherence based on incentives.

\section{Discussion}

Taken together, evidence indicates that smoking (both current and former, passive and active) is associated with: risk of being infected with $M$. tuberculosis, risk of developing $\mathrm{TB}$, risk of developing more severe $\mathrm{TB}$, and risk of dying of TB. In many cases, there is also statistically significant and strong dose-response relationship between these risks and smoking -both in terms of average quantity smoked and number of years smoked. These relationships are not explained away by controlling for such potentially confounding variables as age, gender, alcohol consumption, and HIV status. Do fea- 
sible physiological mechanisms exist, further supporting the causal nature of these associations? Indeed they do, and are just now becoming better understood. The specific mechanisms are likely to involve both structural changes affecting lung function and altered immune response. $^{2}$

As discussed in the Introduction, these two epidemics -tobacco and TB- are on a collision course. Understanding the impact of smoking on TB outcomes is critically important if we want to control TB. More work needs to be done to further elucidate the mechanisms underlying the impact of smoking on $\mathrm{TB}$, so we know how best to intervene with policy. We need to know whether quitting smoking reduces TB risks. We need to educate the public and practitioners about this association. And because smoking is a substantial risk factor for treatment default, we need to address this risk factor -because treatment default leads to drug resistance, a condition that is much more expensive and difficult to treat.

\section{References}

I. Doll R, Peto R, Wheatley K, Gray R, Sutherland I. Mortality in relation to smoking: 40 years' observations on male British doctors. BMJ |994;309:90|-9| |.

2. Arcavi L, Benowitz NL. Cigarette smoking and infection. Arch Intern Med 2004;164:2206-22I6

3. Gajalakshmi V, Peto R, Kanaka TS, Jha P. Smoking and mortality from tuberculosis and other diseases in India: retrospective study of 43000 adult male deaths and 35000 controls. Lancet 2003;362:507-5I5.

4. Dye C. Epidemiology. In: Davies PDO, ed. Clinical tuberculosis. $3^{\text {rd }}$ ed. London:Arnold, 2003. 21 -42.

5. World Health Organization. Mental health: new understanding, new hope. World Health Report 200I. Geneva:WHO, 200I.

6. Dye C, Scheele S, Dolin P, Pathania V, Raviglione MC. Consensus statement. Global burden of tuberculosis: estimated incidence, prevalence, and mortality by country.WHO Global Surveillance and Monitoring Project. JAMA 1999;282:677-686.

7. Raviglione MC, Snider DE, Jr., Kochi A. Global epidemiology of tuberculosis. Morbidity and mortality of a worldwide epidemic. JAMA 1995;273:220-226.

8. Styblo K. Epidemiology of tuberculosis. In: Broekmans JS, editor. Selected papers. The Hague, The Netherlands: Royal Netherlands Tuberculosis Association, 1991: I-136.

9.Vynnycky E, Fine PE. Lifetime risks, incubation period, and serial interval of tuberculosis. Am J Epidemiol 2000;152:247-263.

10. Guindon GE, Boisclair D. Past, Current and Future Trends in Tobacco Use. Economics of Tobacco Control. Washington, D.C.:World Health Organization, 2003.

II. Mackay J, Eriksen M.The Tobacco Atlas. Geneva, Switzerland:World Health Organization 2002

12. Kaufman NJ, Nichter M. The marketing of tobacco to women: Global perspectives. In: Samet JK, Yoon SY.Women and the tobacco epidemic: challenges for the 2 I st century. Geneva:World Health Organization, 2001:69-98
13. Slama K. Current challenges in tobacco control. Int J Tuberc Lung Dis 2004;8:1160-1 I72.

I4.Adelstein AM, Rimington J. Smoking and pulmonary tuberculosis: an analysis based on a study of volunteers for mass miniature radiography. Tubercle 1967;48:219-226.

15. Edwards JH. Contribution of cigarette smoking to respiratory disease. Br J Prev Soc Med 1957;1 1: 10-21.

16. Lowe CR. An association between smoking and respiratory tuberculosis. Br Med J 1956;2:108I-1086.

17. Kuemmerer JM, Comstock GW. Sociologic concomitants of tuberculin sensitivity. Am Rev Respir Dis 1967;96:885-892.

18. Brown KE, Campbell AH. Tobacco, alcohol and tuberculosis. Brit J Dis Chest 1961;55:150-158.

19. Lewis JG, Chamberlain DA. Alcohol consumption and smoking habits in male patients with pulmonary tuberculosis. Brit J Prev Soc Med 1963;17:149-152.

20. Davies PD, Yew WW, Ganguly D, et al. Smoking and tuberculosis: the epidemiological association and immunopathogenesis. Trans R Soc Trop Med Hyg 2006;100:291-298.

21.Yach D, Hawkes C, Epping-Jordan JE, Galbraith S. The World Health Organization's Framework Convention on Tobacco Control: implications for global epidemics of food-related deaths and disease. J Public Health Policy 2003;24:274-290.

22. Maurya V, Vijayan VK, Shah A. Smoking and tuberculosis: an association overlooked. Int J Tuberc Lung Dis 2002;6:942-951. 23. Liu BQ, Peto R, Chen ZM, et al. Emerging tobacco hazards in China: I. Retrospective proportional mortality study of one million deaths. BMJ 1998;3 |7: I4 I I- I 422.

24. Lam TH, Ho SY, Hedley AJ, Mak KH, Peto R. Mortality and smoking in Hong Kong: case-control study of all adult deaths in [998. BM] 200I;323:36I-362.

25. Gupta PC, Pednekar MS, Parkin DM, Sankaranarayanan R. Tobacco associated mortality in Mumbai (Bombay) India. Results of the Bombay Cohort Study. Int J Epidemiol 2005; 34(6): 1395- 1402.

26. Sitas F, Urban M, Bradshaw D, Kielkowski D, Bah S, Peto R. Tobacco attributable deaths in South Africa. Tob Control 2004;13:396-399.

27. Yu GP, Hsieh CC, J P. Risk factors associated with the prevalence of pulmonary tuberculosis among sanitary workers in Shanghai. Tubercle 1988;69:105-II2.

28. Leung CC, Yew WW, Chan CK, et al. Smoking and tuberculosis in Hong Kong. Int J Tuberc Lung Dis 2003;7:980-986.

29. Leung CC, Li T, Lam TH, et al. Smoking and Tuberculosis among the Elderly in Hong Kong. Am J Respir Crit Care Med 2004; I70: 1027-1033. 30. Tocque K, Bellis MA, Beeching NJ, Syed Q, Remmington T, Davies PD. A case-control study of lifestyle risk factors associated with tuberculosis in Liverpool, North-West England. Eur Respir J 2001;18:959-964. 31. Tekkel M, Rahu M, Loit HM, Baburin A. Risk factors for pulmonary tuberculosis in Estonia. Int J Tuberc Lung Dis 2002;6:887-894.

32. Kolappan C, Gopi PG. Tobacco smoking and pulmonary tuberculosis. Thorax 2002;57:964-966.

33. Crampin AC, Glynn JR, Floyd S, et al. Tuberculosis and gender: exploring the patterns in a case control study in Malawi. Int J Tuberc Lung Dis 2004;8: 194-203.

34. Altet MN, Alcaide J, Plans P, et al. Passive smoking and risk of pulmonary tuberculosis in children immediately following infection.A case-control study. Tuber Lung Dis 1996;77:537-544.

35. Alcaide J, Altet MN, Plans P, et al. Cigarette smoking as a risk factor for tuberculosis in young adults: a case-control study. Tuber Lung Dis. 1996;77:1 12-116.

36. Ariyothai N, Podhipak A, Akarasewi P, Tornee S, Smithtikarn S, Thongprathum $\mathrm{P}$. Cigarette smoking and its relation to pulmonary tuberculosis in adults. Southeast Asian J Trop Med Public Health 2004:35:219-227. 
37. Buskin SE, Gale JL,Weiss NS, Nolan CM. Tuberculosis risk factors in adults in King County, Washington, 1988 through 1990. Am J Pub Health 1994;84: I750-1756.

38. Miguez-Burbano MJ, Burbano X, Ashkin D, et al. Impact of tobacco use on the development of opportunistic respiratory infections in HIV seropositive patients on antiretroviral therapy. Addict Biol 2003;8:39-43. 39. Lienhardt C, Fielding K, Sillah J, et al. Investigation of the risk factors for tuberculosis: a case-control study in three countries in West Africa. Int J Epidemiol 2005;34:9|4-923.

40. Nisar M, Williams CSD, Ashby D, Davies PD. Tuberculin testing in residential homes for the elderly. Thorax 1993;48: I257-I 260.

4I. Abal AT, Nair PC, Sugathan TN, Pawar S. Influence of smoking on cutaneous delayed-type hyper sensitivity reaction by tuberculin skin test. Respir Med 2003;97:672-675.

42. Hussain H,Akhtar S, Nanan D. Prevalence of and risk factors associated with Mycobacterium tuberculosis infection in prisoners, North West Frontier Province, Pakistan. Int J Epidemiol 2003;32:794-799.

43. den Boon S, van Lill SW, Borgdorff MW, et al. Association between smoking and tuberculosis infection: a population survey in a high tuberculosis incidence area. Thorax 2005;60:555-557.

44. Solsona J, Cayla JA, Nadal J, et al. Screening for tuberculosis upon admission to shelters and free-meal services. Eur J Epidemiol 200I; 17:123-128.

45. McCurdy SA, Arretz DS, Bates RO. Tuberculin reactivity among California Hispanic migrant farm workers. Amer J Indust Med 1997;32:600-605.

46. Anderson RH, Sy FS, Thompson S, Addy C. Cigarette smoking and tuberculin skin test conversion among incarcerated adults. Am J Prev Med 1997; |3:175-181.

47. Plant AJ,Watkins RE, Gushulak B, et al. Predictors of tuberculin reactivity among prospective Vietnamese migrants: the effect of smoking. Epidemiol Infect 2002;128:37-45.
48. Chang KC, Leung CC, Tam CM. Risk factors for defaulting from antituberculosis treatment under directly observed treatment in Hong Kong. Int J Tuberc Lung Dis 2004;8: 1492-1498.

49. Thomas A, Gopi PG, Santha T, et al. Predictors of relapse among pulmonary tuberculosis patients treated in a DOTS programme in South India. Int J Tuberc Lung Dis 2005;9:556-56I.

50. Santha T, Renu G, Frieden TR, et al. Are community surveys to detect tuberculosis in high prevalence areas useful? Results of a comparative study from Tiruvallur District, South India. Int J Tuberc Lung Dis 2002;7:258-265

51. Organization World Health. Revised international definitions in tuberculosis control. Int J Tuberc Lung Dis 2001;5:213-215.

52. Al-Hajjaj MS, Al-Khatim IM. High rate of non-compliance with antituberculosis treatment despite a retrieval system: a call for implementation of directly observed therapy in Saudi Arabia. Int J Tuberc Lung Dis. 2000;4:345-349.

53. Altet-Gómez MN,Alcaide J, Godoy P, Romero MA, Hernández del Rey I. Clinical and epidemiological aspects of smoking and tuberculosis: a study of I3,038 cases. Int J Tuberc Lung Dis. 2005;9:430-436.

54. Musellim B, Erturan S, Sonmez Duman E, Ongen G. Comparison of extra-pulmonary and pulmonary tuberculosis cases: factors influencing the site of reactivation. Int J Tuberc Lung Dis. 2005;9: I 220-I 223.

55. Balbay O,Annakkaya AN, Arbak P, Bilgin C, Erbas M. Which patients are able to adhere to tuberculosis treatment? A study in a rural area in the northwest part of Turkey. Jpn J Infect Dis. 2005;58: I52-I58. 56. Davidson H, Schluger NW, Feldman PH, Valentine DP, Telzak EE, Laufer FN. The effects of increasing incentives on adherence to tuberculosis directly observed therapy. Int J Tuberc Lung Dis. 2000;4:860-865

57. Combs DL, O'Brien RJ, Geiter LJ. USPHS Tuberculosis short-course chemotherapy trial: effectiveness, toxicity, and acceptability. Ann Intern Med. 1990; I | 2:397-406. 